\title{
Relationship of Adaptation and Homesickness in Rantau Students in Faculty of Psychology of Muhammadiyah Purwokerto University
}

\author{
Elfrida Khoerunnisa, Gisella Arnis Grafiyana*
}

Faculty of Psychology, Universitas Muhammadiyah Purwokerto, Jl. KH. Ahmad Dahlan 53182, Banyumas, Indonesia

*Corresponding author gisella.arnis@ump.ac.id

Article history: Received: 11 January 2020 Received in revised form: 28 June 2020 Accepted: 10 May 2021 Published online: 09 August 2021

\begin{abstract}
Today, many students use the term homesick to describe their situation when they miss their family, are sick, or feel uncomfortable with the situation in their new environment. One emergence of homesickness is a poor adaptation of the student in the new environment. A good adaptation will help the individual create a sense of comfort and happiness in his new environment. This study aims to examine the relationship between adaptation and homesickness in rantau students. The subjects in this study selected by the criteria were rantau students from Faculty of Psychology, Universitas Muhammadiyah Purwokerto, living in boarding houses around campus and not having relatives in Purwokerto with total 35 respondents. This research used quantitative method and for collecting the data using adaptations scales of Archer et al.'s Homesickness Questionnaire and Behavioral Adaptation owned by Umdatun Watsiqoh. The results of the correlation test of the two variables, it shows that there is no correlation between adaptation and homesickness. The correlation of adaptation and homesickness has a negative relationship or inversely related to the correlation coefficient value of -0.086 , but the relationship was not proven significant because the significance value obtained $(\mathrm{p}>0,05)$.
\end{abstract}

Keywords: Adaptation; Homesickness; Rantau Students.

(C) 2021 Penerbit UTM Press. All rights reserved

\subsection{INTRODUCTION}

The development of the era, in line with the development of education, is different from the past where education today has become an obligation for every individual, because education is one way to improve the quality of life of the individual itself. This ultimately requires individuals to get good quality education by finding educational institutions that are far better, even for people who are in remote cities or villages, they are willing to choose educational institutions that are far away, in order to obtain good quality education. Not infrequently some of them choose to live outside their hometown. Choosing to migrate outside this city needs to be considered by these parents and individuals. Not a few of the parents are concerned about the condition of their children outside the city, especially about their health, the concern of these parents ultimately affects the condition of the individual, the individual feels sad because he is not healthy, sad because there are no parents who usually care for him when he is sick, or even sad because there are no friends or relatives who want to care for him. Supported by the results preliminary study of Devita \& Ratih (2015) which shows that in the first year of rantau students, they have difficulty adapting to their new environment and feel lonely because of the absence of parents around them. Cindy \& Agoes (2016) also stated that rantau students have a high likelihood of feeling lonely due to environmental changes.

As stated by Thurber \& Walton (2007) individuals who are likely to experience homesickness are those who are just starting lectures, especially in the first year of lectures. According to Stroebe et al., (2002) homesickness refers to a negative emotional state because it is separated from the house and the closest figure that is characterized by longing and strong thinking about all things related to the house accompanied by the difficulty of adaptation to the new environment. Homesickness is a state of distress caused by individuals separating from where they live (Thurber \& Walton, 2007). Homesickness is characterized by a strong cognition about the home and matters relating to attachment to certain objects. From this description, it can be concluded that homesickness is the emergence of feelings or emotions caused by thoughts and longings about the home and the people closest to those who are separated to continue their education. This is explained in the research conducted by Mozafrinia \& Tavafian (2014) that homesickness can result in several obstacles, such as negative thoughts and feelings, stress, frustration, negative emotions, unwillingness to learn, and loss of interest in life.

Students who experience homesickness, cannot adapt well, this has an impact on the individual's psychic, ranging from decreased learning motivation, depressed, bad mood, even loneliness (feeling lonely). So that this adaptation becomes important for individuals who experience homesickness, so they can adjust the conditions in their environment. Strengthened by Strengthened by Desmita 2009 research that adaptation is one of the important conditions for the formation of a person's mental and mental health. According to Schindehutte \& Morris (2001) adaptation can be defined as the actions of entrepreneurs and their teams in processing information inputs from their environment and making quick adjustments. The ability to adapt to the environment is the ability to respond quickly when changes occur (Gibbons et al., 2004). Denison \& Mishra (1995) said adaptation theory places an emphasis on the ability of organizations to accept, interpret and translate disturbances from the external environment into internal norms that lead to survival or success. 
Based on the theories and phenomena that occur, for this reason, researchers are interested in further studying the relationship between one's adaptation and the longing experienced by foreign students who are required to be away from home.

\subsection{LITERATURE REVIEW}

a)

Adaptation

Haber and Runyon (1984) argue that self-adjustment is a condition desired by an individual as a result of the continuous application of effective adjustments throughout his life. In line with Bal and Singh (2015) adjustment is a process in which individuals learn certain behaviors to deal with situations that are in harmony with their environment. According to Mesidor and Sly (2016), adjustment is the process by which a person tries to balance needs with existing obstacles in his environment, adjustments experienced by overseas students including cultural, social, academic, and psychological adjustments. Haber \& Runyon (1984) explained that aspects of adjustment are perception of reality, ability to deal with stress and anxiety, positive self-image, ability to express emotions well, have good interpersonal relationships.

b) Homesickness

Mozafarinia and Tavafian (2014) explain the notion of longing is a situation that tends to bring up negative emotions, with the characteristics of not stopping thinking about home, losing friends in the village, the desire to be in a place similar to home, and can even cause physical complaints.

Longing is one thing that often happens to students who are required to separate from home at various universities in the world. Not only interferes with daily activities but also homesick can hamper the process of studying abroad. Longing causes some inhibiting problems such as a reluctance to learn, loss of enthusiasm for life, negative thoughts and feelings, stress, frustration, negative emotions, and others. Hewstone, Stroebe, Vliet, and Willis (2002) states that longing makes someone lose the atmosphere of his hometown which causes him to have difficulty being able to adapt to the new environment. As stated by Hewstone et al., (2002) there are five main aspects to know whether someone has a longing and determines the level of longing that someone has longed for family, longing for friends, loneliness, difficulty in adjusting, and contemplation. about home.

Stroebe, Vliet, Hewstone, and Willis (2002) describe longing as consisting of 5 dimensions: longing (longing for parents, family, home and feeling missed by family), loneliness (feeling lonely, unloved, isolated from the environment and feeling the loss of the closest person), miss friends (miss acquaintances, friends, people who are trusted and look for a familiar face), difficulty adapting (difficulty adapting to new situations and habits, feeling uncomfortable and losing direction in a new environment), and thinking of home (individuals think that the situation is old (home) is better than the current situation, regretting the decision to leave the old environment, thinking repeatedly about the house and thinking repeatedly about the past).

\subsection{METHODOLOGY}

The research variable used in this study is the dependent variable which is homesickness while the independent variable is adaptation. The population used in this study were students of the Faculty of Psychology, University of Muhammadiyah Purwokerto who were overseas students of the 2017 and 2018 batches because those students still actively come to campus and commonly living around campus. The data collection process used closed questionnaires through google form with a total of 35 respondents. The technique used in sampling in this study was purposive sampling because the participants needed had to be in accordance with criteria such as the desired variables, such as: rantau students, living in boarding houses (in the kos) around campus and not having relatives in Purwokerto. As stated by Sugiyono (in Satryawan, 2016) the comparative method is one method that aims to compare the existence of a variable or more, on two or more different samples, or at different times. The sample was taken from students in the 3rd and 5th semester at the Faculty of Psychology, Universitas Muhammadiyah Purwokerto, with a number of different students from each semester. The reason for sampling is because students in semester 3 and 5 have started to go directly to the field to interact directly with the community and time to visit homes and families which is far less than when they were still students in semester 1.

Measuring instruments in research are adaptations of Archer et al's Homesickness Questionnaire (in Chair, Harrison, \& Deckard, 2010) and Behavioral Adaptation owned by Umdatun Watsiqoh. The items used to measure homesickness numbered 32, while the items to measure adaptation totaled 29. There were 4 choices of answers to homesickness behavior in the form of Always, Often, Sometimes, and Never, then 4 ranges of answer choices from numbers 1 to 4 starting from the ones most rarely appears to frequently appear.

The validity used in this study is the content validity, Content validity One type of validity is tested by comparing the instrument with the material used, followed by the instrument grid in the form of the variables used and indicators as references and item numbers (Sugiyono, 2015). In this study, the corrected item-total correlation coefficient is used if the number of items tested is relatively small, ie less than 30 (Saifuddin Anwar, 2003). The item used can be said to be valid if the value of the corrected item total correlation $\geq 0.25$. To measure reliability in this study using the value of Alpha Cronbach. On the word of Azwar (in Istanto \& Engry, 2019) that the reliability of the measuring instrument is considered good if the coefficient value is between 0 to 1.00 . The higher the reliability coefficient until close to 1.00 states that the higher the reliability. Conversely, the more the coefficient of reliability approaches 0 , stating that the reliability is lower. All tests in this study used the help of the SPSS Statistics 25 program for windows.

The data analysis technique used in this study is the Pearson bivariate correlation test, but before that first, the following validity and reliability tests are performed validity and reliability test was conducted to meet the standard then the bivariate pearson correlation test will be performed. This is done to find out how the relationship between the dependent variable with the independent variable. Whether to have a strong relationship or not, as well as a negative relationship or actually have a positive relationship. 


\subsection{RESULTS}

In an attempt to see the validity of the research, a correlation between items test and a reliability test were done, followed by a relationship test, each of which results were described as follows:

After processing the data, the following research results have been obtained:

a)

Correlation Between Items

Table 1 Correlation between items test results for homesickness questionnaire

\begin{tabular}{|c|c|c|c|}
\hline No & Question Item & $\begin{array}{c}\text { Correlation } \\
\text { Coefficient Value }\end{array}$ & Conclusion \\
\hline 1 & I can't concentrate at the Academy because I'm always thinking about home & 0,575 & Valid \\
\hline 2 & I hardly ever think about my home & 0,592 & Valid \\
\hline 3 & Thinking about home makes me cry & 0,252 & Valid \\
\hline 4 & I dream about my friends at home & 0,622 & Valid \\
\hline 5 & If given the choice, I would rarely home phone & 0,699 & Valid \\
\hline 6 & If I had the opportunity, I would hardly ever visit home during the school year & 0,713 & Valid \\
\hline 7 & I get really upset when I think about home & 0,730 & Valid \\
\hline 8 & It upsets me if I am unable to phone home & 0,299 & Valid \\
\hline 9 & I can't concentrate on my work & 0,506 & Valid \\
\hline 10 & I feel empty inside & 0,503 & Valid \\
\hline 11 & I should avoid going home because it would be too upsetting & 0,686 & Valid \\
\hline 12 & I wish I had never come to the Academy & 0,723 & Valid \\
\hline 13 & I dream about my home & 0,537 & Valid \\
\hline 14 & I try to shut off thinking about my home & 0,724 & Valid \\
\hline 15 & The people here annoy me & 0,778 & Valid \\
\hline 16 & I can't seem to settle here at the Academy & 0,802 & Valid \\
\hline 17 & I often dream about my family back home & 0,466 & Valid \\
\hline 18 & I feel as if I've left part of me at home & 0,450 & Valid \\
\hline 19 & I blame myself for having come to training & 0,728 & Valid \\
\hline 20 & If I could go home for the weekend, I would feel excited to coming back to the Academy & 0,713 & Valid \\
\hline 21 & I hate this place & 0,781 & Valid \\
\hline 22 & I feel restless here & 0,612 & Valid \\
\hline
\end{tabular}

Based on the results of the correlation between items conducted using the SPSS Statistics 25 program for windows, the correlation between items test results obtained for the homesickness and adaptation variables seen from the corrected item total correlation value. In each of these measurement tools, the item can be said to be valid as measure one variable of the corrected item total correlation value $\geq$ 0.25 . Based on table 1 for homesickness, variables each the corrected item total correlation value is $0,252-0,802$ and table 2 for the adaptation variable, each the corrected item total correlation value is $0,307-0,616$.

table

Table 2 Correlation between items test results for adaptation questionnaire

\begin{tabular}{clcc}
\hline No & \multicolumn{1}{c}{ Question Item } & $\begin{array}{c}\text { Correlation } \\
\text { Coefficient Value }\end{array}$ & Conclusion \\
\hline 1 & I try to make other people feel good & 0,353 & Valid \\
2 & I try to make others important and respected & 0,379 & Valid \\
3 & I try to be close when talking to other people & 0,355 & Valid \\
4 & When I speak, I think about how other people feel & 0,331 & Valid \\
5 & I often make jokes in tense situations & 0,616 & Valid \\
6 & When I'm nervous, I often make jokes about it & 0,539 & Valid \\
7 & When I feel embarrassed, I often make jokes about it & 0,601 & Valid \\
8 & People who think I have a high sense of humor & 0,535 & Valid \\
9 & When speaking, I have problems with the words & 0,382 & Valid \\
& spoken & 0,610 & Valid \\
10 & I sometimes don't choose the word well & 0,307 & Valid \\
11 & I sometimes use one word when I interpret other & & Valid \\
\hline
\end{tabular}


b) Reliability Results

Table 3 Homesickness questionnaire reliability test results

\begin{tabular}{cc}
\hline Cronbach's Alpha & Nof Items \\
\hline 0,937 & 22 \\
\hline
\end{tabular}

Table 4 Adaptation questionnaire reliability test results

\begin{tabular}{cc}
\hline Cronbach's Alpha & Nof Items \\
\hline 0,804 & 12
\end{tabular}

The reliability test in this study used the Cronbach alpha formula computational technique. Reliability measurements use values on alpha cronbach, which if the coefficient value is between 0 to 1.00 will be considered good. To be considered reliable, the coefficient value must reach $\geq 0.70$. Based on the results of the reliability test using the statistical SPSS 25 for windows, the reliability of the homesickness scale of 0.937 (on table 3 ) and the adaptation scale of 0.804 (on table 4) can be said, so that both scales are reliable.

c) Correlation Results

Correlation test in this study uses the total of the two items that have gone through the statistical process in SPSS 25 for Windows bivariate pearson correlation.

Table 5 Bivariate pearson correlation test results

\begin{tabular}{cccc}
\hline Variables & $\mathbf{N}$ & $\begin{array}{c}\text { Pearson } \\
\text { Correlation }\end{array}$ & Sig. (2-tailed) \\
\hline $\begin{array}{c}\text { Homesickness \& } \\
\text { Adaptation }\end{array}$ & 35 & -.086 & .625 \\
\hline Adaptation & 35 & -.086 & .625 \\
\hline
\end{tabular}

The correlation of adaptation and homesickness that is shown on table 5 has a negative relationship or inversely related to the correlation coefficient value of -0.086 , which means the greater the process of adaptation, the smaller the appearance of homesickness in individuals although not significant. But the relationship was not proven significant because the significance value obtained ( $p>0.05)$, it means that the hypothesis that there is a relationship between homesickness and adaptation is not proven or rejected.

\subsection{DISCUSSION AND RECOMMENDATION}

Based on the results of the validity test showed that the two scales, namely the scale of homesickness and adaptation are valid, and based on the results of the reliability test showed that the two scales have quite high reliability. Based on the correlation test of the two variables, it shows that there is not a correlation between adaptation and homesickness. The correlation of adaptation and homesickness has a negative relationship or inversely related to the correlation coefficient value of -0.086 , which means the greater the process of adaptation, the smaller the appearance of homesickness in individuals. Conversely, the smaller the adaptation process carried out on individuals, the greater the homesickness that occurs in these individuals. Unfortunately this relationship was not proven in this study because the significance value obtained $(\mathrm{p}>0.05)$ so there is a relationship between the two variables is not proven or rejected.

The results of this study were againsted by previous research conducted by Istanto and Engry (2019) who explained the relationship between social support and homesickness for rantau students who came from outside Java at Widya Mandala Catholic University in Surabaya, Pakuwon City Campus. In that study explained that the big homesickness is influenced by social support. Therefore, to make individuals not have high homesickness, there needs to be high social support from new people around them. Other studies that support the existence of this study, were conducted by Maya Yasmis, Zulfarnain, and Daulay (2017) who explained the picture of homesickness in new students in the boarding school environment. In that study explained that homesickness can be influenced by factors of age, gender, number of visits, ethnicity, and area of origin. Very interesting because in this study such results were not proven, this could be because overseas students were not too far from Purwokerto so they could spend their weekend time going home. Even though during semester 3-5 they do not give much time to go home because the fieldwork takes up a lot of time, but this can also be a distraction for those who are homesick in their home city.

There are several factors that influence homesickness in accordance with Shuchter \& Zisook (in Kristanto et al., 2017) including disturbing experience factors, sadness due to loss of attachment, trying to maintain attachment, and the presence of feelings of anxiety, anger, and guilt. Disturbing experiences can be obtained from the first experience when attending lectures or while in the process of adaptation in his new environment. This sadness can occur because of separation from parents, relatives, friends, and those closest to him. But it seems that our respondents can handle feelings of separation and focus on the assignments given by them. In connection with efforts to maintain attachment to the family, individuals try to maintain the atmosphere received by the environment by maintaining good communication with the new environment and their families. Meanwhile, feelings of anxiety, anger, and guilt are caused due to a deep sense of longing with his family, so that it raises feelings of anxiety to quickly return home and make him feel guilty due to the decision taken to leave home. This study was not really shown because their home is quite near so they can easily be going home if they still enough time on the weekend. 


\section{Research Limitations and Recommendations}

As for some limitations in the implementation of this study, namely: this research uses google form for distributing questionnaires and this makes it difficult for researchers to meet and interact directly with the subject. Then there are limitations in delivering an explanation when there are some items that are difficult to understand in determining the appropriate answer. Other factors which are beyond the control of the researcher that occur can be conditions and situations that the subject is not good. there is boredom in working on the questionnaire because the number of items is quite a lot.

\subsection{CONCLUSION}

Based on the results of the above research, it shows that both of these scales are valid totaling 22 and 12, and have a fairly high reliability. From the results of the study also showed that there is a negative relationship of adaptation and homesickness obtained based on the results of the correlation test with a correlation coefficient of -0.086 and the significance value obtained $(p>0.05)$, it means that there the relationship homesickness and adaptation is not proven or rejected. Although the results of the study show that there is no relationship between homesickness and adaptation, there is still the possibility that this study can be explored more deeply and broadly considering the distance of overseas students, the intensity of return and also activities during campus as factors that need to be considered for further research.

\section{References}

Bal, B. S., \& Singh, D. (2015). An Analysis of the Components of Emotional Maturity and Adjustment in Combat Sport Athletes. American Journal of Applied Psychology, 4(1), 13-20.

Denison, D. R., \& Mishra, A. K. (1995). Toward a Theory of Organizational Culture and Effectiveness. Organization Science, 6(2), 204-223

Gibbons, Patrick, T., Rosemary, K., \& Geraldine, L. (2004). Adaptability and Performance Effect of Business Level Strategies: An Empirical Test. Irish Studies Review, 16, 57-64. https://doi.org/10.1080/0967088042000228950

Gregory S Longo. (2010). Homesickness in College Students: The Moderating Effect of Religiousness on the Relationship Between Homesickness and Maladjustment. (Master's thesis, Virginia Polytechnic Institute and State University). Retrieved from http://hdl.handle.net/10919/31661 Retrieved date: 06 January 2020.

Haber, A., \& Runyon, R. P. (1984). Psychology of Adjustment. Illionis: The Dorsey Press.

Hewstone, M., Stroebe, M., Vliet, T. V., \& Willis, H. (2002). Homesickness among Students in Two Cultures: Antecedents and Consequences. British Journal of Psychology, 93(2), 147-168.

Istanto, T. L. \& Engry, A. (2019). Hubungan antara Dukungan Sosial dan Homesickness pada Mahasiswa Rantau yang Berasal dari Luar Pulau Jawa di Universitas Katolik Widya Mandala Surabaya Kampus Pakuwon City. Jurnal Experientia, 7(1), 19-30.

Mesidor, J. K., \& Sly, K. F. (2016). Factors that contribute to the Adjustment of International Students. Journal of International Students, 6(1), 262-282.

Mozafarinia, F., \& Tavafian, S. S. 2014. Homesickness and Coping Strategies Among International Students Studying in University Technology Malaysia. Health Education and Health Promotion, 2(1), 53-61.

Schindehutte, M., \& Morris, M. H. (2001). Understanding Strategic Adaptation In Small Firms. International Journal of Entrepreneurial Behaviour \& Research, 7(3), 84-107. https://doi.org/10.1108/EUM0000000005532

Stroebe, M., Van Vliet, T., Hewstone, M., \& Willis, H. (2002). Homesickness Among Students In Two Cultures: Antecedents And Consequences. British Journal of Psychology, 93(2), 147-168. https://doi.org/10.1348/000712602162508

Sugiyono. (2015). Metode Penelitan Pendidikan (Pendekatan Kuantitatif, Kualitatif, dan R\&D). In Alfabeta. ALFABETA.

Thurber, C. A., \& Walton, E. (2007). Preventing and Treating Homesickness. Pediatrics, 119(1): 192-201. https://doi.org/10.1542/peds.2006-2781 